\title{
Effect of telephone contact on further suicide attempts in patients discharged from an emergency department: randomised controlled study
}

\author{
Guillaume Vaiva, François Ducrocq, Philippe Meyer, Daniel Mathieu, Alain Philippe, Christian Libersa, Michel \\ Goudemand
}

\begin{abstract}
Objective To determine the effects over one year of contacting patients by telephone one month or three months after being discharged from an emergency department for deliberate self poisoning compared with usual treatment.

Design Multicentre, randomised controlled trial.

Setting 13 emergency departments in the north of France. Participants 605 people discharged from an emergency department after attempted suicide by deliberate self poisoning. Intervention The intervention consisted of contacting patients by telephone at one month or three months after discharge from an emergency department for attempted suicide to evaluate the success of recommended treatment or to adjust treatment. Control patients received treatment as usual, in most cases referral back to their general practitioner.

Main outcome measures The primary outcome measures were proportion of participants who reattempted suicide, number of deaths by suicide, and losses to follow-up at 13 months' follow-up. Secondary outcome measures were types and number of contacts with health care.

Results On an intention to treat basis, the three groups did not differ significantly for further suicide attempts, deaths by suicide, or losses to follow-up: contact at one month (intervention 23\% (34/147) v controls 30\% (93/312), difference $7 \%, 95 \%$ confidence interval $-2 \%$ to $15 \%)$, three months $(25 \%$ (36/146) v $30 \%$, difference $5 \%,-4 \%$ to $14 \%$ ). Participants contacted at one month were less likely at follow-up to report having reattempted suicide ( $12 \% v 22 \%$ in control group, difference $10 \%, 2 \%$ to $18 \%$ ).

Conclusion Contacting people by telephone one month after being discharged from an emergency department for deliberate self poisoning may help reduce the number of reattempted suicides over one year.
\end{abstract}

\section{Introduction}

People who have attempted suicide are at high risk of further attempts (12\%-30\%) or completing suicide (1\%-3\%), within a year. ${ }^{1-8}$ Most patients discharged directly from emergency care are considered at the lowest short term psychopathological risk or best looked after by their family. When patients are referred to community services, however, they are not assessed for compliance with treatment or treatment success.

A review of controlled studies of treatment strategies for people who have attempted suicide found few methods that sig- nificantly reduced the repetition of suicidal behaviour. ${ }^{9}{ }^{10}$ A nonsignificant lower rate of repeated self harm was found in people who had attempted suicide for the first time and were offered easy access to a trained psychiatrist. ${ }^{11}$ A controlled study that assessed the usefulness of telephone contact at four and eight months after suicide attempts, in addition to usual treatment, found no significant difference between the intervention and control groups in number of further suicide attempts at one year. ${ }^{12}$ The researchers concluded that the method was nevertheless useful because it offered patients who had never received psychiatric care before their index suicide attempt the chance of contact with health professionals.

We systematically contacted patients by telephone one or three months after an attempted suicide by deliberate self poisoning to determine the effect on reattempted suicide over one year. The intervention also included an attempt to enhance compliance with treatment and brief crisis intervention if needed.

\section{Participants and methods}

Our study was carried out in 13 emergency departments in the north of France. Eligible patients were those aged between 18 and 65 years who had attempted suicide by drug overdose, had been examined by a psychiatrist who agreed to their discharge from the emergency department, could give the name of their general practitioner, could be contacted by telephone, and gave written consent for being contacted. We excluded homeless patients and those addicted to illegal drugs.

\section{Study design}

We randomised one group of participants to telephone contact at one month after a suicide attempt and the other to contact at three months (figure). We compared the intervention groups with a control group that consisted of usual treatment (no telephone contact) during the 12 months of follow-up. For every patient in each of the intervention groups we randomised one patient to the control group.

\section{Randomisation}

In each department patients were allocated to a group according to the number in an opaque sealed envelope. The allocation sequence was provided by a statistician uninvolved in the assessment of patients. Patients were randomised to either telephone contact or usual treatment in blocks of eight (2:2:4 per block) on the basis of a computer generated list of pseudorandom 
numbers. We used two strata for the randomisation process: one for patients who had attempted fewer than four suicides in the past three years and one for those who had attempted more than four suicides in the past three years. For each stratum the patients were assigned by random allocation to telephone contact at either one month or three months. No change was possible after allocation, this being verified by the staff responsible for randomisation. The allocation list was stored in tamper proof envelopes in a locked cabinet, accessible only to authorised staff.

\section{Sample size}

To produce significant differences for change in suicidal behaviour after dialectic cognitive therapy, Linehan et al needed a population of 44 participants. ${ }^{13}$ More recently, using a similar method to ours, Guthrie et al reached statistical significance with 95 participants. ${ }^{9}$ Compared with these studies, the psychotherapy involved in our study was less specific, but our telephone interventions took place over a shorter period at defined times. To reach statistical significance we required a population four times larger than that of Guthrie et al $(n=400)$. Assuming that $30 \%$ of the participants would not be contactable by telephone and that $25 \%$ would be lost to follow-up, we included 600 people in our study.

\section{Baseline assessments}

At the baseline assessment data were collected on personal details; stay in the emergency department; details of the suicidal crisis; and mental disorders using the minimal international neuropsychiatric interview for Diagnostic and Statistical Manual of Mental Disorders, fourth edition, the revised symptom checklist 90 , and Beck's hopelessness scale. ${ }^{14-16}$

\section{Interventions}

Psychiatrists with at least five years' experience in managing suicidal crises telephoned the participants. None of the psychiatrists had met the participants. Telephone contact was abandoned if unsuccessful after three attempts on three different days and at two different times (midday or evening).
The principle of contacting participants was to go back over the treatment recommended in the emergency department: if treatment was difficult to follow a new one was suggested or if patients were considered at high risk of suicide an urgent appointment was made at the emergency department in which they had originally been treated. The psychotherapeutic approach used was psychological support, mainly based on empathy, reassurance, explanation, and suggestion. The experimental intervention therefore included an attempt to enhance compliance with treatment and to provide brief crisis intervention when needed.

The participants' general practitioners were given details of the telephone contact and its conclusions. If participants could not be contacted, their general practitioners were informed by letter.

\section{Outcome data assessments}

A specially trained research psychologist, blind to allocation group, assessed the outcome, by telephone.

Participants self reported any further suicide attempts, but these were recorded only if they met a standardised definition. ${ }^{7}$ Throughout the study period a clinical research assistant visited the 13 emergency departments to validate the data by checking the records on all suicide attempts, deaths, or further suicide attempts.

The assessment included information about the use of health services based on a well established method for recording data on health economics. ${ }^{17}$ If participants could not be contacted for the final assessment we telephoned their general practitioner, checked the attendance files and medical records of the emergency departments, and sent a letter to the registrar general's office to check if the participant had died. ${ }^{18}$

\section{Data analysis}

We analysed the data using SAS version 8.2. Firstly, we compared the groups on an intention to treat basis, including all participants, regardless of whether their assigned follow-up had taken place. We considered as adverse outcomes any further suicide attempts, deaths by suicide, and losses to follow-up.

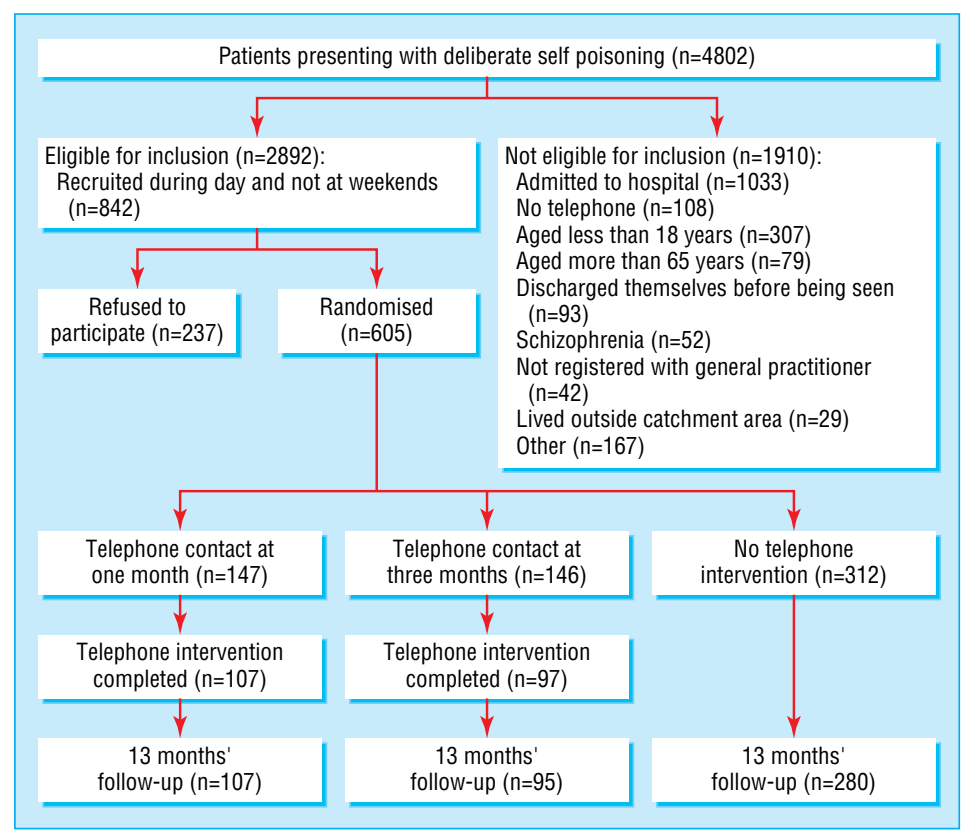

Progress of participants through trial 
Table 1 Baseline characteristics of participants assigned to telephone contact at one month or three months after attempted suicide or to usual treatment (controls). Values are numbers (percentages) unless stated otherwise

\begin{tabular}{|c|c|c|c|}
\hline \multirow[b]{2}{*}{ Characteristic } & \multirow[b]{2}{*}{ Control group $(n=312)$} & \multicolumn{2}{|c|}{ Intervention groups } \\
\hline & & $\begin{array}{l}\text { Telephone contact at one month } \\
\qquad(\mathrm{n}=147)\end{array}$ & Telephone contact at three months ( $n=146)$ \\
\hline Mean (SD) age (years) & $35(11)$ & $38(12)$ & $35(11)$ \\
\hline \multicolumn{4}{|l|}{ Sex: } \\
\hline Women & $221(71)$ & $115(78)$ & $105(72)$ \\
\hline Men & $91(29)$ & $32(22)$ & $41(28)$ \\
\hline Married & $159(51)$ & $79(54)$ & $66(45)$ \\
\hline Employment & $200(63)$ & $90(61)$ & $92(63)$ \\
\hline Mean (SD) duration (hours) of emergency stay & $18(8)$ & $20(10)$ & $18(8)$ \\
\hline Accompanied by partner during emergency stay & $175(56)$ & $82(56)$ & $88(60)$ \\
\hline Received psychiatric counselling & $250(80)$ & $122(83)$ & $105(72)$ \\
\hline Psychiatric treatment arranged & $65(21)$ & $35(24)$ & $34(23)$ \\
\hline $\begin{array}{l}\text { Mean (SD) time (days) to psychiatric } \\
\text { consultation }\end{array}$ & $12(14)$ & $8(7)$ & $14(30)$ \\
\hline$>4$ suicide attempts in past three years & $28(9)$ & $13(9)$ & $13(9)$ \\
\hline $\begin{array}{l}\text { Mean (SD) No of different drugs used for } \\
\text { suicide attempt }\end{array}$ & $1.7(1)$ & $1.8(1)$ & $1.8(1)$ \\
\hline Alcohol with overdose & $140(45)$ & $47(32)$ & $52(36)$ \\
\hline Communication of suicidal ideation & $94(30)$ & $53(36)$ & $42(29)$ \\
\hline Evidence of planning & $69(22)$ & $28(19)$ & $15(10)$ \\
\hline Wanted to die & $6(2)$ & $3(2)$ & $3(2)$ \\
\hline Suicide note & $22(7)$ & $12(8)$ & $16(11)$ \\
\hline Poor compliance with treatment & $78(25)$ & $38(26)$ & $26(18)$ \\
\hline Self prescribed & $87(28)$ & $49(33)$ & $36(25)$ \\
\hline Family history of mental disorders & $84(27)$ & $45(30)$ & $48(33)$ \\
\hline Painful disease & $34(11)$ & $16(11)$ & $8(7)$ \\
\hline Chronic disease & $40(13)$ & $28(19)$ & $16(11)$ \\
\hline Social and affective isolation & $103(33)$ & $56(38)$ & $48(33)$ \\
\hline Stressful life event in past six months & $146(47)$ & $84(57)$ & $66(45)$ \\
\hline $\begin{array}{l}\text { Mean (SD) score on revised symptom checklist } \\
90 \text { (range } 0-180 \text { ) }\end{array}$ & $110(63)$ & $115(62)$ & $124(74)$ \\
\hline $\begin{array}{l}\text { Mean (SD) score on Beck hopelessness scale } \\
\text { range } 0-20)^{*}\end{array}$ & $8.3(5)$ & $8.3(4)$ & $9.2(5)$ \\
\hline
\end{tabular}

${ }^{*} 0=$ no hopelessness.

Secondly, we analysed the data of participants successfully contacted at one month and at three months, to assess the effect of telephone contact on further suicide attempts. We compared normally distributed variables using the $t$ test and we compared qualitative data using Fisher's exact test.

\section{Results}

Thirteen emergency departments in the north of France recruited patients over a six month period, during the day but not at weekends. Overall, 605 patients were included. The mean age of participants did not differ from that of non-participants. The sex ratio of participants was three men for every seven women compared with four men for every six women for non-participants $\left(\mathrm{P}=0.0001, \chi^{2}=47, \mathrm{df}=1\right)$.

\section{Attrition}

Overall, $70 \%$ of participants in both of the intervention groups were successfully contacted by telephone. Compared with the contacted participants, fewer of the non-contactable ones were depressed (35\% (31/89) v 48\% (98/204); $\mathrm{P}=0.05, \chi^{2}=3.8$, $\mathrm{df}=1)$ or had a somatisation disorder $(13 \%(\mathrm{n}=11) \vee 24 \%$ $\left.(\mathrm{n}=49) ; \mathrm{P}=0.03, \chi^{2}=4.8, \mathrm{df}=1\right)$. No difference was found for age, sex, personal factors, number of previous suicide attempts, or severity of psychopathological disorders.

At the end of the 13 month follow-up period we assessed all the included participants, regardless of whether their assigned telephone intervention had taken place. Fifty seven were lost to follow-up (9\%). These were more often men (38\% (22/57) v 27\%
(147/545); $\mathrm{P}=0.07)$, had arrived at the emergency department on their own $(59 \%(\mathrm{n}=34) v 42 \%(\mathrm{n}=229) ; \mathrm{P}=0.01)$, were more likely to be drunk $(53 \%(\mathrm{n}=30)$ v $40 \%(\mathrm{n}=218) ; \mathrm{P}=0.05)$, and had fewer social phobias $(2 \%(\mathrm{n}=1) v 13 \%(\mathrm{n}=71) ; \mathrm{P}=0.02)$.

Six participants died: two among the intervention groups (one a possible suicide from a road traffic incident and the other cancer), two in the control group (both by suicide), and two who were lost to follow-up (one from suicide and one from an ischaemic vascular attack).

The randomised groups did not differ for personal characteristics, psychopathological assessments, previous suicide attempts, or ongoing treatment in the emergency departments (table 1).

\section{Effect of contact by telephone}

On an intention to treat basis, the three groups did not differ significantly for proportion with an adverse outcome $(\mathrm{P}=0.25$, table 2): contact at one month (one death (cancer), 23\% (34/147) $v 30 \%$ (93/312) in control group, difference 7\%, 95\% confidence interval $-2 \%$ to $15 \%$ ); contact at three months (one death from suicide, $5 \%(36 / 146)$ v $30 \%$ in control group, difference $5 \%$, $-4 \%$ to $14 \%$ ); comparison between contact at one month and contact at three months $(23 \% v 25 \%$, difference $2 \%,-11 \%$ to $8 \%)$.

The number of participants contacted at one month who reattempted suicide was significantly lower than that of controls $\left(12 \% \quad(13 / 107)\right.$ v $22 \% \quad(62 / 280) ; \quad \chi^{2}=4.7, \quad \mathrm{df}=1, \quad \mathrm{P}=0.03$, difference $10 \%, 95 \%$ confidence interval $2 \%$ to $18 \%)$. This differ- 
Table 2 Results of intention to treat analysis in participants assigned to telephone contact one month or three months after attempted suicide or to usual treatment (controls). Values are numbers (percentages) unless stated otherwise

\begin{tabular}{|c|c|c|c|c|c|c|}
\hline \multirow[b]{2}{*}{ Variable } & \multirow[b]{2}{*}{$\begin{array}{c}\text { Control group } \\
(\mathrm{n}=312)\end{array}$} & \multicolumn{4}{|c|}{ Intervention groups } & \multirow[b]{2}{*}{$P$ value } \\
\hline & & $\begin{array}{l}\text { Telephone contact at one } \\
\text { month }(n=147)\end{array}$ & $\begin{array}{l}\text { Difference in proportions } \\
(95 \% \mathrm{Cl})\end{array}$ & $\begin{array}{l}\text { Telephone contact at three } \\
\text { months }(n=146)\end{array}$ & $\begin{array}{c}\text { Difference in proportions } \\
(95 \% \mathrm{Cl})\end{array}$ & \\
\hline $\begin{array}{l}\text { Participants who } \\
\text { reattempted suicide }\end{array}$ & $59(19)$ & $24(16)$ & $3(-5$ to 10$)$ & $20(14)$ & $5(-2$ to 1$)$ & $0.37 ; \chi^{2}=1.97$ \\
\hline Deaths by suicide & $2(1)$ & 0 & & 1 (1) & & \\
\hline Lost to follow-up & $32(10)$ & $10(7)$ & $4(-2$ to 9$)$ & $15(10)$ & $0(-6$ to 6$)$ & $0.46 ; \chi^{2}=1.56$ \\
\hline Adverse outcomes & $93(30)$ & $34(23)$ & $7(-2$ to 15$)$ & $36(28)$ & $5(-4$ to 14$)$ & $0.25 ; \chi^{2}=2.77$ \\
\hline
\end{tabular}

ence was seen over the first six months after telephone contact. No deaths from suicide occurred in this group.

For participants contacted at three months, the number who attempted further suicide was not significantly lower than that of controls $(17 \%(16 / 95) \cup 22 \% ; \mathrm{P}=0.27$, difference $5 \%,-4 \%$ to $14 \%)$.

\section{Attendance for treatment}

Participants in the interventions groups talked about their attempted suicide with their general practitioner more often than the controls (table 3).

Of the 107 participants contacted at one month, 72 were ordinary calls (lasting 5-10 minutes), 22 concerned crisis intervention (15-45 minutes), and 13 detected participants at high risk of suicide. Seven of the 72 participants who seemed alright at the time of contact attempted suicide during the following year. Of the 22 participants who required crisis intervention, five attempted suicide within a year. Thirteen participants were sent to the emergency department; 10 were considered by the psychiatrist as being at risk and eight of these were admitted to hospital. Only one of these 13 patients reattempted suicide, six months later.

\section{Discussion}

Contacting people by telephone one month after attempted suicide by deliberate self poisoning may help reduce the proportion of people who reattempt suicide. Telephone contact also enables the detection of people at high risk of further suicide attempts and timely referral for emergency care.

In our study, the proportion of participants who reattempted suicide in the control group, which received treatment as usual, is similar to the data in the literature. ${ }^{310} 19$ A systematic review noted no deaths or morbidity at one year in participants of eight of 10 studies; the remaining two studies showed a brief reduction in further suicide attempts. ${ }^{13}{ }^{20}{ }^{21}$ Recently, Guthrie et al assessed the efficacy of a series of psychoanalytically based consultations at the patient's home during the month after a suicide attempt. ${ }^{9}$ This study focused on patients who were not admitted to hospital after their suicide attempt, a population similar to ours. Although the reduction in number of further suicide attempts seems greater in Guthrie et al's study, the telephone contact used was easier and cheaper to set up than in our study.

We made no attempt to control for the non-specific effects of psychotherapy, since ours was a pragmatic study. We compared a specific intervention with treatment as usual in France for patients who harm themselves.

Three quarters of the eligible patients agreed to participate. Our recruitment rate was much higher than in previous studies, showing that the patients were more open to telephone contact than to an appointment in the psychiatric clinic. ${ }^{9}$

One limitation of our study was that 48 of the attempted suicides occurred before the telephone contact at one month. One option would have been to test the effect of earlier contact, between days 15 and 21 after the first suicide attempt, to see if a larger number of reattempted suicides could have been avoided.

Another limitation of our study was the number of patients who could not be contacted by telephone. We believe this to be the main reason for the negative result of the intention to treat analysis. In our study the decision to abandon telephone contact was based on the strict criterion of three unsuccessful attempts. When the final assessment was made, this criterion was lifted and so we were able to include the maximum number of patients possible. We therefore recommend that the number of telephone contacts should be unlimited, to ensure maximum contact with patients.

We thank the following staff of the emergency departments: Sylvie Dupont (Catholic University of Lille), Benoît Averland (Douai), Marianne Babe (Roubaix), Claude Meurisse (Valenciennes), Jean Bernard Campagne (Dunkerque), Pierre Valette (Arras), Nadine Ruolt (Lens), Jean Michel Bourez (Tourcoing), Marianne Sandlars (Denain), Yves Fichaux (Seclin), Olivier Brochart (Douai), and Fabienne Saulnier (Lille); the psychiatrists who con-

Table 3 Use of healthcare resources during 13 months' follow-up in participants contacted by telephone one month or three months after attempted suicide

\begin{tabular}{|c|c|c|c|c|c|}
\hline \multirow[b]{2}{*}{ Variable } & \multirow[b]{2}{*}{ Control group $(\mathrm{n}=280)$} & \multicolumn{4}{|c|}{ Intervention groups } \\
\hline & & $\begin{array}{l}\text { Telephone contact at one } \\
\text { month }(n=107)\end{array}$ & P value ${ }^{*}$ & $\begin{array}{c}\text { Telephone contact at three } \\
\text { months }(n=95)\end{array}$ & P value* \\
\hline Talked with general practitioner about suicide & $204(73)$ & $82(87)$ & $0.004 \dagger$ & $72(88)$ & $0.004 \ddagger$ \\
\hline Psychotropics & $115(41)$ & $43(46)$ & 0.38 & $30(36)$ & 0.36 \\
\hline Psychotherapy & $104(37)$ & $42(45)$ & 0.18 & $31(38)$ & 0.96 \\
\hline \multicolumn{6}{|l|}{ Types of psychotropics: } \\
\hline Anxiolytics & 16 & 15 & 0.33 & 15 & 0.69 \\
\hline Antidepressants & 19 & 26 & & 20 & \\
\hline Admission to hospital for psychiatric reason & $62(22)$ & $21(22)$ & 0.99 & $21(24)$ & 0.77 \\
\hline Mean (SD) No of admissions to hospital & 0.39 (1) & $0.30(0.6)$ & 0.41 & $0.29(0.7)$ & 0.42 \\
\hline Mean (SD) duration of hospital stay (days) & $24(32)$ & $21(13) \S$ & 0.79 & 27 (19)ף & 0.82 \\
\hline
\end{tabular}

${ }^{*}$ Comparison with control group.

$\mathrm{tdf}=1, \chi^{2}=8.5$.

$\dagger \mathrm{df}=1, \chi^{2}=8.5$.
$\ddagger \mathrm{df}=1, \chi^{2}=8.2$

$\S 95 \%$ confidence interval -17.8 to 12.0 .

ๆ95\% confidence interval -18.0 to 22.5 . 
tacted the participants: Olivier Cottencin, Christian Bondu, Christophe Debien, and Virginie Boss; the clinical research assistants who helped with follow-up: Stéphane Duhem and Anne Laure Demarty; the French World Health Organization collaborating centre in mental health (Jean-Luc Roelandt, Lille); and the Groupement d'Etude et de Prevention du Suicide (Jean-Jacques Chavagnat, Poitiers).

Contributors: GV helped design the study, contacted the participants, reviewed the literature, and wrote the paper. He is guarantor. FD contacted the participants and reviewed the literature. PM supervised the conduct of the study and contacted participants. DM supervised the conduct of the study and assessed participants for eligibility. AP helped design the study and carried out the statistical analysis. CL helped design the study, and carried out the statistical analysis. MG helped design the study. All authors reviewed the manuscript.

Funding: This study was funded by a hospital clinical research gran (PHRC98), a state region contract plan, a subsidy from the regional hospitalization agency,.

Competing interests: None declared.

Ethical approval: This study was approved by the ethical committee of the University Hospital Centre of Lille (CCPPRB 98/33).

1 Foster T, Gillespie K, McClelland R. Mental disorders and suicide in Northern Ireland BrJ Psychiatry 1997;170:447-52.

2 Hawton K, McKeown S, Day A, Martin P, O'Connor M, Yule J. Evaluation of out-patient counselling compared with general practitioner care following overdoses. Psychol Med 1987;17:751-6

3 Holley HL, Fick G, Love EJ. Suicide following an inpatient hospitalization for a suicide attempt: a Canadian follow-up study. Soc Psychiatry Psychiatr Epidemiol 1998;33:543-51.

4 Repetition of attempted suicide: results from the WHO/EU multicentre study on parasuicide, repetition-prediction part. 7th European Symposium on suicide and suicidal behaviour. Ghent: Ghent University Press, 1998.

5 Ojehagen A, Danielsson M, Traskman-Bendz L. Deliberate self-poisoning: treatment follow-up of repeaters and nonrepeaters. Acta Psychiatr Scand 1992;85:370-5.

6 Ryngnestad T. A 15-year follow-up study after deliberate self poisoning. Nordisk Laegeforen 1997;117:3065-9.

7 Schmidtke A, Bille-Brahe U, DeLeo D, Kerkhof A, Bjerke T, Crepet P, et al. Attempted suicide in Europe: rates, trends and sociodemographic characteristics of suicide attempters during the period 1989-1992. Results of the WHO/EURO multicentre study on parasuicide. Acta Psychiatr Scand 1996;93:327-38.

\section{What is already known on this topic}

Up to $15 \%$ of patients who attempt suicide by deliberate self poisoning eventually commit suicide

Few interventions of proved efficacy exist for these patients

The interventions are expensive and never concern all people who attempt suicide

\section{What this study adds}

Telephone contact of people one month after attempted suicide may reduce the number who reattempt suicide
8 Van Heeringen C, Jannes S, Buylaert W, Henderick H, De Bacquer D, van Remoortel J. The management of non-compliance with referral to out-patient after-care among attempted suicide patients: a controlled intervention study. Psychol Med 1995;25:96370 .

9 Guthrie E, Kapur N, Mackway-Jones K, Chew-Graham C, Moorey J, Mendel E, et al. Randomised controlled trial of brief psychological intervention after deliberate self poisoning. BMJ 2001;323:135-8.

10 Hawton K, Fagg J. Suicide, and other causes of death, following attempted suicide. Br J Psychiatry 1988;152:359-66.

11 Evans MO, Morgan HG, Hayward A, Gunnell DJ. Crisis telephone consultation for deliberate self-harm patients: effects on repetition. BrJ Psychiatry 1999;175:23-7.

12 Cedereke M, Monti K, Ojehagen A. Telephone contact with patients in the year after a suicide attempt: does it affect treatment attendance and outcome? A randomised controlled study. Eur Psychiatry 2002;17:82-91.

13 Linehan MM, Armstrong HE, Suarez A, Allmon D, Heard HL. Cognitive-behavioral treatment of chronically parasuicidal borderline patients. Arch Gen Psychiatry 1991;48:1060-4.

14 Lecrubier Y, Sheehan DV, Weiller E, Amorim P, Bonora I, Sheehan KH. The mini international neuropsychiatric interview (M.I.N.I.). A short diagnostic structured interview: reliability and validity according to the CIDI. Eur Psychiatry 1997;12:224-31.

15 Beck AT, Weissman A, Lester D, Trexler L. The measurement of pessimism: the hopelessness scale.J Consult Clin Psychol 1974;42:861-5.

16 Pariente P, Guelfi JD. SCL-90-R. Inventaire d'autoévaluation de la psychopathologie chez l'adulte. 1ère partie. Inventaires multidimensionnels. Psychiatr Psychobiol 1990;5:49-63.

17 Beecham J, Knapp N. Costing psychiatric interventions. In: Thornicroft G, Brewin C, Wing JK, eds. Measuring mental health needs. London: Royal College of Psychiatrists, 1992:163-83.

18 Van der Sande R, van Rooijen L, Buskens E, Allart E, Hawton K, van der Graaf Y, et al. Intensive in-patient and community intervention versus routine care after attempted suicide. A randomised controlled intervention study. Br J Psychiatry 1997;171:35-41.

19 Harris EC, Barraclough B. Suicide as an outcome for mental disorders. A meta-analysis. BrJ Psychiatry 1997;170:205-28.

20 Van der Sande R, Buskens E, Allart E, van der Graaf Y, van Engeland H. Psychosocial intervention following suicide attempt: a systematic review of treatment interventions. Acta Psychiatr Scand 1997;96:43-50.

21 Salkovskis PM, Atha C, Storer D. Cognitive-behavioural problem solving in the treatment of patients who repeatedly attempt suicide. A controlled trial. Br J Psychiatry 1990;157:871-6.

(Accepted 8 March 2006)

bmj.com 2006;332:1241

University Hospital of Lille, School of Medicine, France

Guillaume Vaiva psychiatrist

François Ducrocq psychiatrist

Daniel Mathieu professor of crisis care medicine

Christian Libersa professor of pharmacology

Michel Goudemand professor of psychiatry

University Hospital of Lille, School of Medicine, 6 rue du Professeur Laguesse,

59037 Lille cedex, France; Institut National de la Santé Et de la Recherche

Médicale (INSERM U513), School of Medicine, Créteil, France

Guillaume Vaiva psychiatrist

INSERM U513, School of Medicine, Créteil, France

Alain Philippe researcher in sociodemography

General Hospital of Valenciennes, France

Philippe Meyer psychiatrist

Correspondence to: G Vaiva gvaiva@chru-lille.fr 